\title{
Optically Induced Valence Tautomeric Interconversion in Cobalt Dioxolene Complexes
}

\section{Alessandra Beni, ${ }^{\mathrm{a}}$ Chiara Carbonera, ${ }^{\mathrm{b}}$ Andrea Dei, ${ }^{*, \mathrm{a}}$ Jean-François Létard, ${ }^{\mathrm{b}}$ Roberto Righini, Claudio Sangregorio ${ }^{\mathrm{a}}$ and Lorenzo Sorace ${ }^{\mathrm{a}}$}

\author{
${ }^{a}$ Dipartimento di Chimica dell'Università, LAMM UdR INSTM, Via della Lastruccia, 3, Sesto Fiorentino, 50019 \\ Firenze, Italy \\ ${ }^{b}$ Institut de Chimie de la Matière Condensée de Bordeaux, UPR CNRS No 9048, 87 Av. du Doc. A. Schweitzer, \\ Université Bordeaux 1, F-33608 Pessac, France \\ ${ }^{c}$ Lens Laboratory, Via Nello Carrara 1, Sesto Fiorentino, 50019 Firenze, Italy
}

\begin{abstract}
A descoberta de que vários complexos de cobalto-dioxoleno exibem bi-estabilidade magnética foto induzida foi descrita recentemente. Este fenômeno encontra-se sempre associado a processos de interconversão de tautômeros de valência entre espécies de cobalto(III) baixo spin e de cobalto(II) alto spin. Enfatiza-se, nesta revisão, a forte correlação formal existente entre estes processos e o efeito LIESST (Light-Induced Excited Spin State Trapping) exibido por vários complexos de ferro(II) que sofrem interconversão de spin. A dinâmica da relaxação da espécie meta-estável fotoinduzida para o estado fundamental é discutida em termos de processos adiabáticos no âmbito da teoria de Jortner da relaxação multifônica sem radiação.
\end{abstract}

The discovery that a number of cobalt-dioxolene complexes undergo photoswitchable behavior was reported in the recent past. This phenomenon is always associated with valence tautomeric interconversion processes involving low-spin cobalt(III) and high-spin cobalt(II) species. Herein is stressed the strong formal correlation existing between these processes and the LIESST (Light-Induced Excited Spin State Trapping) effect shown by several iron(II) complexes undergoing spin crossover interconversion. The dynamics of the relaxation of the photoinduced metastable species to the ground state is discussed in terms of non-adiabatic processes within the Jortner theory of radiationless multiphonon relaxation.

Keywords: valence tautomerism, redox isomerism, photochromism, photoinduction, photomagnetism, semiquinone, radical ligand

\section{Introduction}

The study of molecular systems whose physical properties can be reversibly changed and controlled following a variation of an external parameter constitutes an appealing perspective for the realization of molecular scale electronic devices. ${ }^{1,2}$ In particular molecules showing photoreactivity or photochromic properties are of potential interest as materials for optical data storage. ${ }^{3}$ Although undoubtedly attractive, the uncompleted comprehension of the factors affecting the photochromic behavior has hampered the possibility of designing new systems following a predetermined strategy.

Photochromism is defined as a light stimulated reversible interconversion of two isomers of a given

*e-mail: andrea.dei@unifi.it chemical species with different electronic absorption spectra. The photoinduced interconversion occurs by irradiating with light source at an appropriate wavelength an absorption band of the molecular system to be converted. The original isomer can in turn be restored by irradiating an appropriate electronic transition of the photoinduced product. Since in general the two species are characterized by different free energies, the photoinduction process yields a metastable product and a thermally induced relaxation process to the ground state may occur depending on the free energy barrier of the relaxation process itself. If this barrier is large, the lifetime of the photoinduced product can be very long. In this case, if the physical properties of the starting material and of the metastable product are different a potential application of the material as switches or display devices can be conceived. 
A dramatic extension of the perspectives of photochromism was given by the discovery that the change of magnetic properties of a molecule and long-range magnetic order effects can be induced by photoexcitation. ${ }^{4-7}$ Following these findings the research was focused on the light induced changes of the optical and magnetic properties of coordination compounds of transition metal ions.

Notwithstanding these efforts the number of coordination compounds showing photoinduced magnetic properties in the solid state is still rather limited. They are some dithienylethylene derivatives, ${ }^{8,9}$ tetracyanoethylene organometallic compounds, ${ }^{10}$ prussian blue analogues,${ }^{11,12}$ spin-crossover ${ }^{13,14}$ and valence tautomeric complexes. ${ }^{15-22}$ As a general paradigm, all of these systems characterized by a spin ground state $\mathrm{S}$ and a orbital momentum L, can be switched in their respective metastable states with spin state $S^{\prime}$ and orbital momentum L' upon optical irradiation. The scheme of the interconversion process is shown in Figure 1.

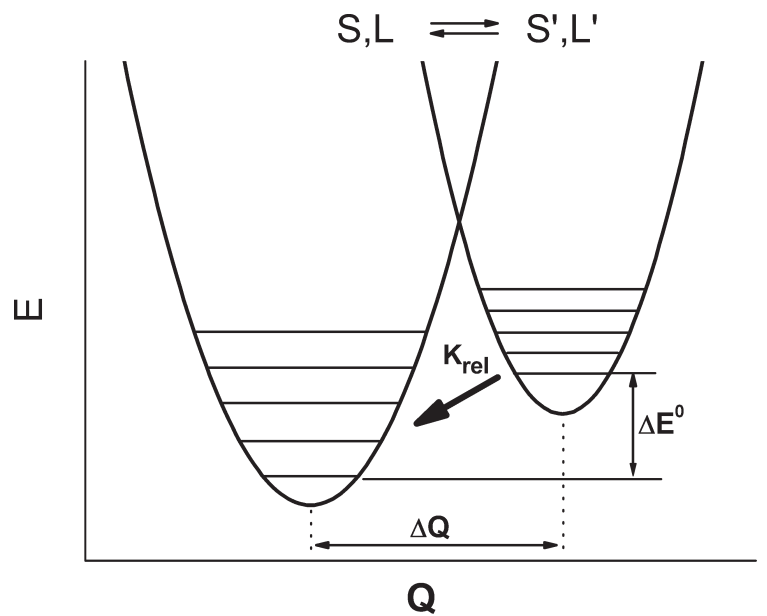

Figure 1. Potential energy wells of S,L and S', L' states as a function of the variation of the totally symmetric normal coordinate $\mathrm{Q}$.

In most part of the examples so far reported, the two interconversion processes involve a change of the electronic population of the anti-bonding metal $\sigma^{*}$ orbitals. This affects the strength of the metal-ligand bond and the exothermic or endothermic character of the interconversion process can be easily predicted. At low temperature, where the free energy changes are largely determined by the enthalpy contributions, the ground state is characterized by stronger metal ligand bonds than the metastable state. Therefore the induced interconversion process involves a change of the bond lengths which in some cases can be as relevant as $10 \%$. This can deeply influence the value of the free energy barrier of the relaxation process. It is currently believed that the possibility of obtaining long lived metastable state at low temperature is strictly connected with large changes of metal-ligand bond lengths. On the other hand since metal-ligand bonds strength decreases in the interconversion process, the density of vibrational states increases, inducing a positive entropy change. Thus as the temperature increases the free energy difference between the two species decreases and it always exists a critical temperature $T_{c}$, at which the free energy difference between the two species vanishes. Therefore in principle any photoinduced interconversion process can also be thermally driven.

The present contribution concerns optical induced valence tautomeric interconversion of cobalt dioxolene complexes. The $3 \mathrm{~d}$ metal coordination chemistry of dioxolene was developed in the last thirty years, showing that these molecules can coordinate in different oxidation states to metal ions. The simple $o$-dioxolene can bind metal ions as di-negative catecholate, mono-negative semiquinonate and neutral quinone. One of the interesting features of the chemistry of these ligands resides in the low degree of delocalisation within the metallacyle chelate ring. This allows a charge localized description of metal dioxolene complexes with well defined oxidation states. The main consequence of this situation is the possibility of observing a peculiar phenomenon, i.e., valence tautomeric interconversion. In fact when in a metaldioxolene adduct the energies of the frontier molecular orbitals of the metal and the ligand are similar, it is possible to observe an intramolecular electron transfer process between two isomers differing in charge distribution according to the general equation:

$\mathrm{M}^{(\mathrm{n}+1)+}-\mathrm{L}^{(\mathrm{m}+1)-}=\mathrm{M}^{\mathrm{n}+}-\mathrm{L}^{\mathrm{m}-}$

Detailed reviews concerning this topic have been reported in the past. ${ }^{15-22}$ Among all the metal dioxolene complexes undergoing valence tautomerism, cobalt derivatives are undoubtedly the most attractive. In all of the reported examples the interconversion involves an intramolecular electron transfer from a coordinated dioxolene ligand to a six-coordinate diamagnetic, low spin $(l s) \mathrm{Co}^{\mathrm{III}}\left(t_{2 g}{ }^{6}\left(\mathrm{O}_{\mathrm{h}}\right)\right)$, yielding a $\mathrm{Co}^{\mathrm{II}}$ coordinated to the one electron oxidized dioxolene species (Scheme 1).

In this species the metal ion is in the high-spin (hs) electronic configuration $\left(t_{2 g}{ }^{5} e_{g}^{2}, \mathrm{~S}=3 / 2\right)$ with a large unquenched orbital contribution. As observed for spincrossover systems, the process is essentially entropy driven, the $\mathrm{Co}^{\mathrm{III}}$ species being favored at low temperatures and the $\mathrm{Co}^{\mathrm{II}}$-ones at high temperatures. ${ }^{23-25}$ It is well established that the transition between the two forms can be also induced by pressure changes ${ }^{26,27}$ or by optical irradiation. The latter aspect, which makes these 


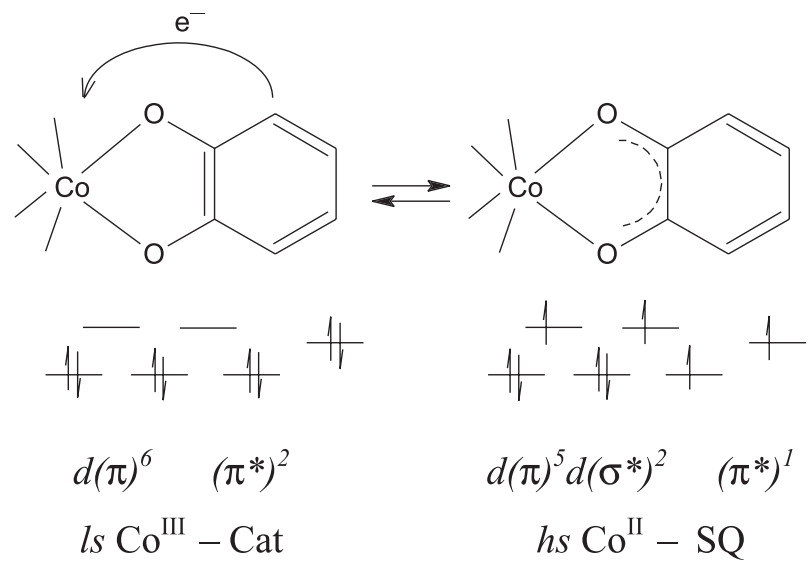

Scheme 1.

compounds of potential technological interest as candidates for molecular switches, is here emphasized.

\section{Solution Studies of Valence Tautomer Process}

The first example of valence tautomerism was reported by Buchanan and Pierpont in $1980 .{ }^{23}$ The EPR spectra and structural and magnetic properties of the solid compound [Co(bpy)(DBCat)(DBSQ)] (bpy = 2,2 'bipyridine, $\mathrm{DBCat}, \mathrm{DBSQ}=$ catecholato and semiquinonato forms of 3,5-di-tert-butyl-o-benzoquinone) were found consistent with the formulation of a diamagnetic cobalt(III) complex coordinated to two dioxolene ligands in different oxidation states, i.e., catecholato and semiquinonato. However the spectral and physical properties of the toluene solution of this compound were found to be temperature dependent and, as supported by magnetic measurements, consistent with the existence of the equilibrium,

\section{$\left[l s-\mathrm{Co}^{\mathrm{III}}(\mathrm{bpy})(\mathrm{DBCat})(\mathrm{DBSQ})\right] \rightleftarrows$ $\left[h s-\mathrm{Co}^{\mathrm{II}}(\mathrm{bpy})(\mathrm{DBSQ})_{2}\right]$}

involving an intramolecular electron transfer between the catecholato ligand and the cobalt(III) metal ion. The tautomeric interconversion results in a change of the electronic configuration from a $S=1 / 2$ ground state (arising from a $l s$ cobalt(III) $t_{2 g}{ }^{6}, \mathrm{~S}=0$, a catecholato $\pi^{* 2}, \mathrm{~S}=0$, and a semiquinonato, $\pi^{*} 1, S=1 / 2$ ) to a system formed by an $h s$ cobalt(II) $\left(t_{2 g}{ }^{5} e_{g}{ }^{2}, \mathrm{~S}=3 / 2\right)$ and two semiquinonato radical ligands. The latter species is characterized by a more complicated spin multiplicity (one doublet, two quartets and one sextet depending on the exchange coupling).

The observed behavior is similar to that observed for spin-crossover interconversions exhibited by some iron(II) complexes. For these systems the process involves a transition between $l s$-iron(II) $\left(t_{2 g}{ }^{6}, \mathrm{~S}=0\right)$ and $h s$-iron(II) $\left(t_{2 g}{ }^{4} e_{g}{ }^{2}, \mathrm{~S}=2\right)$. In both spin-crossover and valence tautomeric interconversions there is a variation of population of the $e_{g}$ orbitals ( $\sigma^{*}$ in character) with a metalligand bond length changes of $0.16-0.22 \AA$ for the iron(II) complexes and $0.18 \AA$ for the cobalt-dioxolene ones.

Ten years ago Adams and Hendrickson showed that when $\left[l s-\mathrm{Co}^{\mathrm{III}}(\mathrm{N}-\mathrm{N})(\mathrm{DBCat})(\mathrm{DBSQ})\right](\mathrm{N}-\mathrm{N}=$ ancillary diazine ligand) in toluene solution was photolyzed with laser pulses on picosecond and nanosecond time scales, the $\left[h s-\mathrm{Co}^{\mathrm{II}}(\mathrm{N}-\mathrm{N})(\mathrm{DBSQ})_{2}\right]$ was generated as transient species, ${ }^{28,29}$ showing for the first time that the valence tautomeric interconversion can be photoinduced. It was also shown that the transient $\left[h s-\mathrm{Co}^{\mathrm{II}}(\mathrm{N}-\mathrm{N})(\mathrm{DBSQ})_{2}\right]$ species relaxed back to the ground state in $10 \mathrm{~ns}$ at room temperature. ${ }^{29}$ The temperature dependence of the relaxation rate in the $140-300 \mathrm{~K}$ range followed the

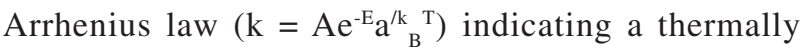
activated process. However below $132 \mathrm{~K} \mathrm{k}$ was found to be constant, suggesting a tunneling relaxation process.

In their extensive contribution the same authors showed the similarity characterizing the relaxation kinetics of valence tautomeric and spin-crossover interconversions. The following factors were found to affect the rate of interconversion of $\left[\mathrm{Co}^{\mathrm{II}}(\mathrm{N}-\mathrm{N})(\mathrm{DBSQ})_{2}\right]$ to $\left[\mathrm{Co}^{\mathrm{III}}(\mathrm{N}-\right.$ $\mathrm{N})(\mathrm{DBCat})(\mathrm{DBSQ})]$ : $(i)$ the metal-dioxolene bond length variation; (ii) the frequency of the active metal-ligand vibrational mode determining the coupling between the two different configurations; (iii) the free energy difference between the two tautomers; (iv) the electronic coupling between the initial and final state. ${ }^{29}$ The observed quantum tunneling rate was consistent with the law theoretically predicted by Jortner and co-workers ${ }^{30}$ for equilibria involving spin crossover complexes. The tunneling process was too fast to allow for the formation of a long-lived metastable state by photoinduction at low temperature.

Further details concerning the electron transfer process occurring in cobalt-dioxolene complexes were obtained by the investigation of a complex formed by a Schiff base tridentate ligand ${ }^{31-33}$ which may exist in five possible oxidation states, but it is usually found to coordinate as mononegative Cat-N-BQ or dinegative radical Cat-N-SQ (Scheme 2).

The cobalt derivative of this ligand can be formulated as $[\mathrm{Co}(\mathrm{III})(\mathrm{Cat}-\mathrm{N}-\mathrm{BQ})(\mathrm{Cat}-\mathrm{N}-\mathrm{SQ})] .{ }^{31}$ It was found to undergo valence tautomeric interconversion in the solid state well above room temperature $(T c=597 \mathrm{~K}) .^{32}$ However both electronic spectra and magnetic susceptibility measurements strongly suggest that in solution the valence tautomeric equilibrium occurs at room temperature. ${ }^{33}$ 


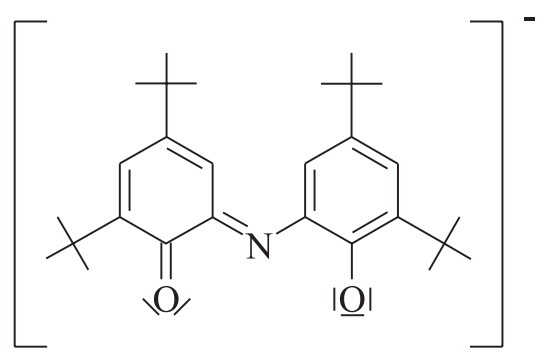

Scheme 2.

Cat $-N-B Q$

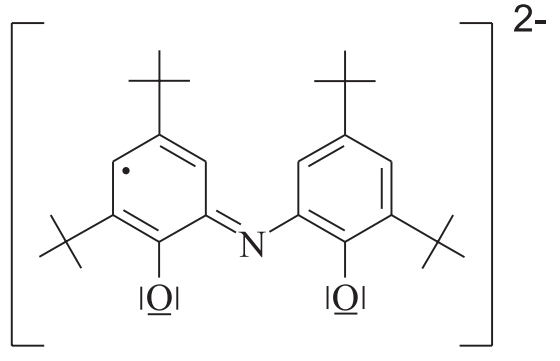

Cat-N-SQ
$\left[l s-\mathrm{Co}^{\mathrm{III}}(\mathrm{Cat}-\mathrm{N}-\mathrm{BQ})(\mathrm{Cat}-\mathrm{N}-\mathrm{SQ})\right] \rightleftarrows\left[h s-\mathrm{Co}^{\mathrm{II}}(\mathrm{Cat}-\mathrm{N}-\mathrm{BQ})_{2}\right]$ $(\mathrm{S}=1 / 2)$ $(\mathrm{S}=3 / 2)$

Time-resolved spectroscopic characterization on femtosecond time scale provided insight into the mechanism of the electron transfer in solution. ${ }^{34} \mathrm{UV}$-vis pump probe transient spectroscopy showed that the process occurs in three distinct steps: (i) the electron transfer between the ligand and the metal is induced by photoexcitation; (ii) an electron redistribution leading to $\left[h s-\mathrm{Co}^{\mathrm{II}}(\mathrm{Cat}-\mathrm{N}-\mathrm{BQ})_{2}\right]$ and (iii) the equilibrium between $\left[h s-\mathrm{Co}^{\mathrm{II}}(\mathrm{Cat}-\mathrm{N}-\mathrm{BQ})_{2}\right]$ and $\left[l s-\mathrm{Co}{ }^{\mathrm{III}}(\mathrm{Cat}-\mathrm{N}-\mathrm{BQ})(\mathrm{Cat}-\mathrm{N}-\mathrm{SQ})\right]$ is thermally restored. The nature of the species forming in step $(i)$ is not well ascertained, but it is probably to be identified with the $\left[l s-\mathrm{Co}{ }^{\mathrm{II}}(\mathrm{Cat}-\mathrm{N}-\mathrm{BQ})_{2}\right]$. The quantitative formation of $\left[h s-\mathrm{Co}^{\mathrm{II}}(\mathrm{Cat}-\mathrm{N}-\mathrm{BQ})_{2}\right]$ occurs in less than 1 $\mathrm{ps}$, whereas the relaxation rate to the ground state occurs with a rate constant of $1.5 \times 10^{9} \mathrm{~s}^{-1}$. This extremely fast process was attributed to the strong electronic coupling between the two interconverting species in the framework of the theory of non-adiabatic multiphonon relaxation theory (see below).

A further study on the $\left[\mathrm{Co}\left(\mathrm{Me}_{4} \text { cyclam }\right)(\mathrm{DBSQ})\right]^{+}$ complex $\left(\mathrm{Me}_{4}\right.$ cyclam = 1,4,8,11-tetramethyl-1,4,8,11tetraazacyclotetradecane) showed more intriguing features. ${ }^{35,36}$ Magnetic susceptibility measurements suggested that this compound is characterized by a triplet ground state due to antiferromagnetic coupling between the cobalt(II) ion and the radical ligand. Femtosecond time resolved spectroscopic characterization in solution showed that excitation of the MLCT band at $400 \mathrm{~nm}$ of this complex induced the formation of a $\mathrm{Co}^{\mathrm{III}}$-Cat species in triplet state (with $\mathrm{Co}^{\mathrm{III}}$ in $\mathrm{t}_{2 \mathrm{~g}}{ }^{5} \mathrm{e}_{\mathrm{g}}{ }^{1}$ configuration). This species decays, with a rate constant of about $5 \times 10^{12} \mathrm{~s}^{-1}$, to another triplet isomer, presumably $l s-\mathrm{Co}^{\mathrm{II}}-\mathrm{SQ}$. The latter transient intermediate decays with a rate constant of $1.4 \times 10^{11} \mathrm{~s}^{-1}$ in a new species which, on the basis of its electronic spectrum, has been assigned to the singlet $\left[\mathrm{Co}^{\mathrm{III}}\left(\mathrm{Me}_{4} \text { cyclam }\right)(\mathrm{DBCat})\right]^{+}$. A third relaxation process finally restores the original
$\left[\mathrm{Co}^{\mathrm{II}}\left(\mathrm{Me}_{4} \mathrm{cyclam}\right)(\mathrm{DBSQ})\right]^{+}$with a rate constant of $6 \times 10^{6}$ $\mathrm{s}^{-1}$. It has to be noted that the lifetime of the last intermediate, $\left[\mathrm{Co}^{\mathrm{III}}\left(\mathrm{Me}_{4} \text { cyclam }\right)(\mathrm{DBCat})\right]^{+}$, is extremely long if one considers that electrochemical data suggest a relevant $(>0.5 \mathrm{eV})$ free energy difference between the [Co $\left(\mathrm{Me}_{4}\right.$ cyclam $\left.)(\mathrm{DBSQ})\right]^{+}$and $\left[\mathrm{Co}\left(\mathrm{Me}_{4} \text { cyclam }\right)(\mathrm{DBCat})\right]^{+}$ species. The relaxation paths are sketched in Scheme 3.

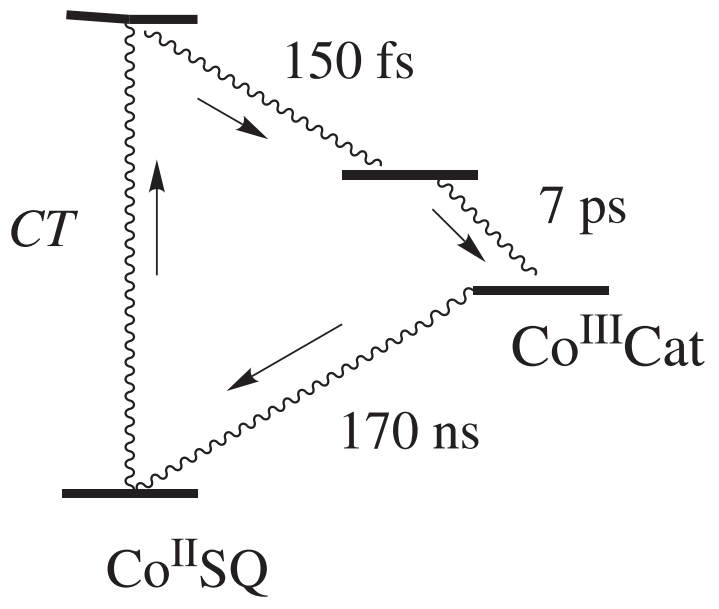

Scheme 3.

\section{Solid State Studies of Valence Tautomer Process}

It is a common practice in the chemical literature to use the distinction between mixed valence, spin crossover and valence tautomerism, although it is rather clear that all these classes of compounds can be described as electronically labile systems with two or more electronic states lying close in energy. This common property leads to the consequence that these systems are controlled by vibronic interactions and are extremely sensitive to the environment. Thus, in addition to the fundamental role of the photophysical properties of the individual molecule, which control the light absorption process, short and long range interactions of the molecule with the environment 
strongly affect the transient stabilization of upper lying electronic states. The latter factors are often difficult to be predicted. This is clearly shown by the following example, concerning the first complex reported to undergo valence tautomeric interconversion in the solid state.

Variable temperature magnetic susceptibility data of $[\mathrm{Co}($ phen $)(\mathrm{DBCat})(\mathrm{DBSQ})]$, where phen $=1,10$ phenantroline, showed that when this compound is recrystallised from methyl-cyclohexane, it can be described as $\left[\mathrm{Co}^{\mathrm{II}}(\mathrm{phen})(\mathrm{DBSQ})_{2}\right]$ in the temperature range 4-300 K. ${ }^{24}$ However the recrystallisation from toluene affords at room temperature a compound of formula $\left[\mathrm{Co}\right.$ II (phen) $\left.(\mathrm{DBSQ})_{2}\right] \cdot \mathrm{C}_{6} \mathrm{H}_{5} \mathrm{CH}_{3}$. Magnetic data showed that it undergoes a thermally driven valence tautomeric interconversion in the temperature range $220-260 \mathrm{~K}$. The transition is abrupt and presents thermal hysteresis of 5 $\mathrm{K}$. The $\left[\mathrm{Co}^{\mathrm{III}}(\mathrm{phen})(\mathrm{DBCat})(\mathrm{DBSQ})\right]$ charge distribution at low temperature and the $\left[\mathrm{Co}^{\mathrm{II}}(\mathrm{phen})(\mathrm{DBSQ})_{2}\right]$ one at room temperature were supported by X-ray structural data. Finally the recrystallisation from chlorobenzene afforded again a solvate undergoing a similar interconversion. In this case the process is not abrupt, but it can be classified as gradual and occurs in the temperature range 130-320 $\mathrm{K}$, without any thermal hysteresis.

The discovery that some cobalt-dioxolene complexes may undergo valence tautomeric interconversion in the solid state by optical perturbation was independently reported by Hayami, Sato et al. and Varret et al. in $2001 . .^{38-40}$ The irradiation of the LMCT band of $\left[\mathrm{Co}{ }^{\mathrm{III}}(\right.$ phen)(DBCat)(DBSQ) $] \cdot \mathrm{C}_{6} \mathrm{H}_{5} \mathrm{CH}_{3}$ complex at $5 \mathrm{~K}$, induced a significant increase of the magnetisation value of the sample. Electronic absorption and IR spectra were found consistent with the formation of $\left[\mathrm{Co}^{\mathrm{II}}(\mathrm{phen})(\mathrm{DBSQ})_{2}\right]$ as metastable product, as later supported by X-ray diffraction. ${ }^{41}$ The lifetime of the metastable product at $5 \mathrm{~K}$ was found to be $330 \mathrm{~min}$. The experiment was reproduced in our laboratory and a life time of 345 min was observed. Finally it was observed that when the sample was heated at $50 \mathrm{~K}$, the original [Co ${ }^{\mathrm{II}}($ phen)(DBCat)(DBSQ)] charge distribution was fully restored following the thermal relaxation of the metastable isomer.

Similar results were obtained with the irradiation of the $\left[\mathrm{Co}(\right.$ tmeda)(DBCat)(DBSQ) $] \cdot 0.5 \mathrm{C}_{6} \mathrm{H}_{5} \mathrm{CH}_{3}$ (tmeda $=$ $\mathrm{N}, \mathrm{N}, \mathrm{N}$ ', N'-tetramethylethylenediamine). ${ }^{42}$ In this case the observed life time of metastable [hs-Co(tmeda) $(\mathrm{DBSQ})_{2}$ ] species was $175 \mathrm{~min}$. For this system it was found that the reverse valence tautomeric reaction could be induced by irradiating the charge transfer band of the metastable product.

These experiments in their essence are in a striking analogy with the discovery of the so called LIESST effect
(Light Induced Excited Spin State Trapping) exhibited by some iron(II) spin crossover complexes. In 1984 Gutlich and coworkers ${ }^{43}$ showed that the irradiation in the region of a charge transfer band of a polycrystalline sample of $\left[\mathrm{Fe}(\mathrm{ptz})_{6}\left(\mathrm{BF}_{4}\right)_{2}\right]$ in its low-spin state at $20 \mathrm{~K}$ allowed the population of an high-spin excited state. In 1986 Hauser showed that the phenomenon was reversible:44 the irradiation of an electronic band of the photoinduced metastable product lead to the recovery of the original state at low temperature (reverse LIESST effect). Ten years later the groups of Hashimoto and Verdaguer, independently, showed that several FeCo Prussian blue analogues, exhibited photoinduced magnetisation at low temperature. ${ }^{7,45,46}$ This process was shown to be due to the valence tautomeric equilibrium:

$l s-\mathrm{Co}^{\mathrm{III}}-l s-\mathrm{Fe}^{\mathrm{II}} \rightleftarrows h s-\mathrm{Co}^{\mathrm{II}}-l s-\mathrm{Fe}^{\mathrm{III}}$

The delay in the discovery of a similar phenomenon involving cobalt-dioxolene complexes must be attributed to the relative small number of research groups working in the area of photoswitchable compounds until the recent past.

In order to reduce the complexity of the electronic structure of cobalt-dioxolene complexes showing valence tautomerism, we designed a simple 1:1 cobalt-dioxolene complex by tuning the redox properties of the $\mathrm{Co}{ }^{\mathrm{II}} / \mathrm{Co}^{\mathrm{II}}$ couple with respect to that of the SQ/Cat one, using different ancillary tetradentate macrocyclic ligands. ${ }^{36}$ We achieved our goal with the synthesis of $[\mathrm{Co}(\mathrm{CTH})($ Phendiox $)] \mathrm{Y}$ complexes $(\mathrm{CTH}=5,7,7,12,14,14$-hexamethyl-1,4,8,11tetraazacyclo-tetradecane; Phendiox $=9,10$-dioxophenanthrene; $\left.\mathrm{Y}=\mathrm{PF}_{6}, \mathrm{I}, \mathrm{BPh}_{4}\right) .{ }^{27}$ These compounds were found to undergo in the solid state temperature and pressure driven valence tautomeric transition,

\section{$\left[\mathrm{Co}{ }^{\mathrm{III}}(\mathrm{CTH})(\mathrm{PhenCat})\right]^{+} \rightleftarrows\left[\mathrm{Co}^{\mathrm{II}}(\mathrm{CTH})(\mathrm{PhenSQ})\right]^{+}$}

Temperature dependent magnetic susceptibility measurements showed that these compounds are diamagnetic at low temperature, but starting from $150 \mathrm{~K}$ they become paramagnetic. As expected in accord with the larger dimension of the Co ${ }^{\text {IISQ }}$ complex, it was found that increasing pressure stabilizes the $\mathrm{Co}^{\mathrm{III}} \mathrm{Cat}$ form. It is worth mentioning that once crystallized from deuterodichloromethane the $\mathrm{PF}_{6}$ complex shows an abrupt transition with thermal hysteresis $\left(\mathrm{T} \uparrow=244 \mathrm{~K}, \mathrm{~T}_{-}=236\right.$ $\mathrm{K})$ whereas the $\mathrm{CH}_{2} \mathrm{Cl}_{2}$ solvate undergoes to a gradual transition $(\mathrm{T} \downarrow=300 \mathrm{~K}) .{ }^{47}$

The irradiation of the compound at $890 \mathrm{~nm}$ and at 410 $\mathrm{nm}$, where absorption bands presumably due to LMCT transitions occur, induces at $10 \mathrm{~K}$, an enhancement of the 

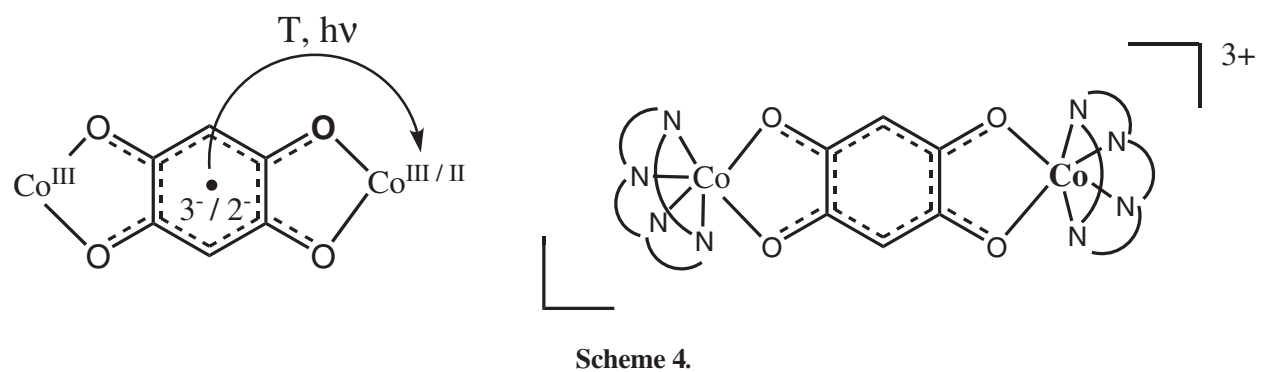

magnetisation (19\% at the photostationary limit). ${ }^{48}$ The low temperature electronic spectrum of the photoinduced metastable product shows at $700 \mathrm{~nm}$ the same absorption band observed in the room temperature electronic spectrum due to the $\left[\mathrm{Co}^{\mathrm{II}}(\mathrm{CTH})(\mathrm{PhenSQ})\right]^{+}$chromophore. The relaxation kinetics of this system will be discussed below.

In order to increase the variety of magnetic behavior of molecules undergoing valence tautomerism we attempted the synthesis of new, polynuclear systems, where a cobalt ion and other paramagnetic metal ions are bridged by a polydioxolene ligand.

The first member of this family was obtained by isolating the $[\mathrm{Co}(\mathrm{CTH})]_{2}(\mathrm{DHBQ})\left(\mathrm{PF}_{6}\right)_{3}$ complex (DHBQ $=$ deprotonated 2,5-di-hydroxy-1,4-benzoquinone), ${ }^{49}$ Scheme 4.

Although the room temperature electronic and IR spectra of this compound strongly support the formulation of the compound as a mixed valence $\mathrm{Co}^{\mathrm{II}}-\mathrm{Co}^{\mathrm{III}}$ bridged by the di-negative tetraoxolene, temperature dependent magnetic susceptibility measurements show the existence of a transition between two different species (Figure 2). Indeed the $\chi \mathrm{T} v s$. $\mathrm{T}$ plot of this compound shows values close to $0.4 \mathrm{emu} \mathrm{mol}^{-1} \mathrm{~K}$ in the range $4-100 \mathrm{~K}$ in agreement with a species characterized by a doublet ground state. Above $100 \mathrm{~K} \chi \mathrm{T}$ increases and reaches the constant value

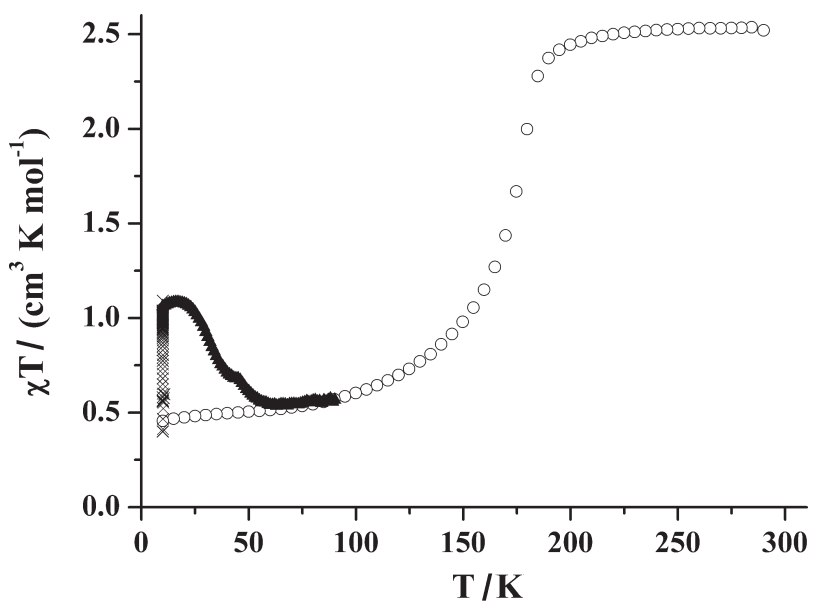

Figure 2. $\chi \mathrm{T} v s$. T curves of $[\mathrm{Co}(\mathrm{CTH})]_{2}(\mathrm{DHBQ})\left(\mathrm{PF}_{6}\right)_{3}$ measured before (empty circles) and after (full triangles) irradiation at $647 \mathrm{~nm}$. Cross symbols show the increase of the $\chi \mathrm{T}$ product with time while irradiating the sample.
$2.53 \mathrm{emu} \mathrm{mol}^{-1} \mathrm{~K}$ at $200 \mathrm{~K}$, which is consistent with the presence of an $\mathrm{S}=3 / 2$ paramagnetic species. The observed behavior is consistent either with the existence of a spincrossover transition involving the Co(II) ion or with a valence tautomeric interconversion involving the $l s-\mathrm{Co}^{\mathrm{III}}$ $\left(\mathrm{DHBQ}^{3-}\right)-l s-\mathrm{Co}^{\mathrm{III}}$ and $h s-\mathrm{Co}^{\mathrm{II}}-\left(\mathrm{DHBQ}^{2-}\right)-l s-\mathrm{Co}^{\mathrm{III}}$ species. The EPR spectrum of this compound at $4 \mathrm{~K}$ shows a strong signal at $g=2.00$, thus supporting the existence of a radical ligand and ruling out the possibility of a spin-crossover equilibrium.

The above interconversion process was shown to be induced by photoperturbation at low temperatures. In fact a change of the $\chi \mathrm{T}$ value from 0.4 to $1.2 \mathrm{emu} \mathrm{mol}^{-1} \mathrm{~K}$ was observed when this derivative was irradiated at $10 \mathrm{~K}$ with 647-676 nm laser lights. Once warmed at $60 \mathrm{~K}$ the magnetic susceptibility recovered the initial value, thus showing that the phenomenon is reversible. Both EPR and reflectivity spectra supported the above suggestions. A closely related dinuclear cobalt-DHBQ derivative has been recently found to exhibit a similar behaviour. ${ }^{50}$ Although from the published magnetic data the nature of the species involved is rather unclear, some of us recently obtained by EPR evidence that interconversion process involves the same species of the original derivative.

All the above discussed examples clearly show that valence tautomeric interconversions in cobalt-dioxolene complexes can be photoinduced at any temperature. However, their potential for technological application is strictly connected with the relaxation kinetics of the photoinduced metastable species to the ground state. In order to develop systems characterized by appropriate photophysical properties, it is therefore necessary to understand the factors affecting the relaxation kinetics of the metastable species.

\section{Theoretical Considerations}

The relaxation of the photoinduced metastable state involves an intersystem crossing process (ISC). In spincrossover complexes the relaxation rates usually become temperature independent below a critical temperature. ${ }^{51}$ This phenomenon is explained in terms of tunnel effect. 
Jortner and co-workers ${ }^{30}$ suggested that the ISC dynamics should be treated as a nonadiabatic process within the framework of radiationless multiphonon relaxation. This theory is expected to work in the limit of strong vibronic coupling between two different spin states in different nuclear configurations. Adams and Hendrickson extended this theory to the analysis of valence tautomerism in cobalt dioxolene systems. ${ }^{29}$ Further developments introduced by Hauser ${ }^{52-55}$ allowed for a more complete picture of the proposed model.

In a simplified view the valence tautomeric interconversion can be described by energy potential diagram shown in Figure 1. The 1:1 cobalt-dioxolene complex may exist in one of the two states, $\mathrm{Co}^{\mathrm{III}}$-Cat and $\mathrm{Co}^{\mathrm{II}}-\mathrm{SQ}$, which are represented by the two harmonic potential energy curves. Since the interconversion involves a change of the Co-O bond length, the reaction coordinate $\mathrm{Q}$ can be assumed to correspond to the total symmetric breathing mode of the complex. In classic kinetics, the relaxation rate from one state to the other is controlled by the thermal energy necessary to overcome the free energy barrier between the two potential curves. In a quantum mechanic approach, the tunneling probability for a non radiative process from a given vibrational level $i$ of the $\mathrm{Co}^{\mathrm{II}}$-SQ state to a vibrational level $k$ of the $\mathrm{Co}^{\mathrm{III}}$-Cat state is given by the Fermi Golden Rule.

If, for the sake of simplicity, we assume that the two states are characterized by the same force constants $f$ and vibrational frequencies $\mathrm{n}$, the energy conservation requires for non-radiative process that $\mathrm{k}=\mathrm{i}+\mathrm{n}$, where $\mathrm{n}=\Delta \mathrm{E} / \mathrm{h} v$ corresponds to the zero-point energy difference between the two harmonic potential curves, i.e., their reciprocal vertical displacement, expressed in units of vibrational quanta. Using the Franck-Condon approximation the $\mathrm{Co}^{\mathrm{II}}$ $\mathrm{SQ} \rightarrow \mathrm{Co}^{\mathrm{III}}$-Cat relaxation rate constant according to Jortner and coworkers ${ }^{30}$ is given by:

$k(T)=\left(2 \pi / h^{2} v\right) g_{f}|V|^{2} G$

where $g_{f}$ is the electronic degeneracy of the ground state, $\mathrm{V}$ is the electronic coupling matrix element including spinorbit coupling, and $\mathrm{G}$ is the thermally averaged nuclear Franck-Condon vibrational overlap factor,

$G(T)=\frac{\Sigma_{\mathrm{i}}\left|<\chi_{\mathrm{i}+\mathrm{n}}\right| \chi_{\mathrm{i}}>\left.\right|^{2} \mathrm{e}^{-\mathrm{ihv} / \mathrm{kT}}}{\Sigma_{\mathrm{i}} \mathrm{e}^{-\mathrm{ihv} / \mathrm{kT}}}$

where $\chi_{i+n}$ and $\chi_{i}$ are the vibrational functions of the $i+n$ and i states, respectively. Since the population of the vibrational states is temperature dependent, the relaxation rate is temperature dependent too. At high temperatures the $\mathrm{G}$ factor is proportional to $\exp (-\Delta \mathrm{E} / \mathrm{kT})$ and then the relaxation rate follows an Arrhenius law. At low temperature where only the vibrational ground state of the $\mathrm{Co}^{\mathrm{II}}$-SQ species is populated, (2) and (3) reduce to:

$\mathrm{k}(\mathrm{T} \rightarrow 0)=\left(2 \pi / \mathrm{h}^{2} v\right) \mathrm{g}_{\mathrm{f}}|\mathrm{V}|^{2}\left|<\chi_{\mathrm{n}}\right| \chi_{0}>\left.\right|^{2}$

It can be shown that under the above assumed conditions,

$\left|<\chi_{n}\right| \chi_{0}>\left.\right|^{2}=\mathrm{S}^{\mathrm{n}} \mathrm{e}^{-\mathrm{S}} / \mathrm{n} !$

where $\mathrm{S}$, the Huang-Rhys factor, is related to the horizontal displacement of the two harmonic potential curves

$S=1 / 2 f \Delta Q^{2} / h v$

Therefore the relaxation rate depends on the values of $\mathrm{V}, \mathrm{S}$ and $\mathrm{n}$. As $\mathrm{S}$ increases and $\mathrm{V}$ and $\mathrm{n}$ decrease, the relaxation process slows down. Thus large changes in the metal-ligand bond lengths, small electronic coupling and small energy differences between the valence tautomers are the prerequisite for observing the photoinduction processes.

In practice for valence tautomeric processes $S$ values are in general large. The electronic coupling $\mathrm{V}$ is controlled by the relative symmetries of the donor and acceptor orbitals. The valence tautomeric interconversion from $\mathrm{Co}^{\mathrm{II}}$ SQ to $\mathrm{Co}^{\mathrm{III}}$-Cat involves as first step the transfer from a $\sigma^{*}\left(\mathrm{e}_{\mathrm{g}}\right)$ orbital to the $\pi^{*}$ (SOMO) orbital of the semiquinonato ligand. Since the two orbitals are orthogonal, it is expected that their mixing and then electronic coupling are negligible. In addition the electron transfer is allowed only between states of same spin multiplicity. Since the $\mathrm{Co}^{\mathrm{II}}-\mathrm{SQ}$ couple gives rise to a triplet and quintet states, the coupling between these states and the singlet ground state of $\mathrm{Co}^{\mathrm{III}}$-Cat can only arise from second order spin-orbit coupling and therefore can be predicted to be very small.

Finally, the above equations predict that small zeropoint energy differences should favor slow relaxation rates, whereas for large differences $(n>5)$ fast relaxation rates should be observed. For iron(II) spin crossover complexes this is experimentally observed, and values of tunneling rate constant $\mathrm{k}(\mathrm{T} \rightarrow 0)$ varying in a wide range $\left(<10^{-6} \mathrm{~s}^{-1}\right.$ and $\left.>10^{8} \mathrm{~s}^{-1}\right)$ have been reported. ${ }^{52}$ Hauser has proposed that $\mathrm{k}(\mathrm{T} \rightarrow 0)$ is related to the critical temperature $\mathrm{T}_{\mathrm{c}}{ }^{52,54} \mathrm{~A}$ low $\mathrm{T}_{\mathrm{c}}$ implies a small $\mathrm{n}$ value and then a slow relaxation process, whereas systems characterized by high $T_{c}$ are expected to be characterized by large $\mathrm{n}$ and fast relaxation rates. The same considerations can be extended to the case of valence tautomerism. In this case the calculated $\mathrm{S}$ and $\mathrm{V}$ 
values, and thermal interconversion temperature in the 200$300 \mathrm{~K}$ range suggest an $\mathrm{n}$ value close to 1 . Under these conditions it is reasonable to expect that at temperatures below $40-50 \mathrm{~K}$ the relaxation process is temperature independent. ${ }^{30}$ At higher temperatures the relaxation rate becomes temperature dependent with effective activation energies smaller than those expected from the classic theory. This occurs because excited vibrational levels of the $\mathrm{Co}^{\mathrm{II}}$ SQ species, having larger overlap with the vibrational levels of the $\mathrm{Co}^{\mathrm{III}}$-Cat form, become populated.

\section{Non Radiative Relaxation in the Solid State}

From the above discussion it is rather clear that the valence tautomeric relaxation is an unimolecular process and therefore a single exponential decay is expected. Therefore when the molecule is in a diluted state like a solution or a glass, the relaxation kinetics is expected to obey to a relationship of the type,

$\gamma(\mathrm{t})=\gamma_{0} \exp (-\mathrm{K}(\mathrm{T}) \mathrm{t})$

where $\gamma(t)$ is the molar fraction of the metastable species at time $\mathrm{t}$ and $\gamma_{0}$ is the photoinduced molar fraction at $\mathrm{t}=0$. This relationship holds if every molecule undergoing valence tautomeric relaxation experiences the same interactions with the environment as $\Delta \mathrm{E}$ is the same for every relaxing centre. In the solid state, the experimental relaxation does not follow the same decay law processes both in the pure tunnelling and thermally activated regimes. The apparent relaxation rate decreases as the process goes on. This behavior is attributed to the inhomogeneous distribution of the relaxing centres in the sample which experience subtle differences in the interactions with the environment. These small differences result in a distribution of $\Delta \mathrm{E}$ values and then of $\mathrm{n}$, which controls the relaxation rates. Even if the range of this distribution is narrow (of the order of $100-500 \mathrm{~cm}^{-1}$ ), the effect on the kinetics is enormous, because of the strong dependence of the relaxation rate on $\Delta \mathrm{E}$ values. For cobaltdioxolene complexes the size of the $\mathrm{CO}^{\mathrm{II}}$-SQ species is in general $5 \%$ larger than that of the $\mathrm{Co}^{\mathrm{III}}$-Cat one. Thus the conversion of a Co ${ }^{\mathrm{II}}$-SQ to $\mathrm{Co}^{\mathrm{III}}$-Cat will reduce the internal pressure in the lattice, stabilising the largest species. As a consequence the relaxation process slows down as it proceeds. Thus in a condensed phase the inhomogeneous distribution of the relaxing centres will produce an evolving distribution of activation energies.

The analysis of the relaxation kinetics of systems with similar distribution of energy barrier can be satisfactorily made by using a stretched exponential decay law: ${ }^{56}$ $\gamma(\mathrm{t})=\gamma_{0} \exp \left(-(\mathrm{K}(\mathrm{T}) \mathrm{t})^{\beta}\right.$

where $\gamma(t)$ and $\gamma_{0}$ have the same meening as in (7) and $\beta$ is a parameter comprised between 0 and 1 , accounting for the distribution of relaxation times.

We have found that the relaxation curve of $[\mathrm{Co}(\mathrm{CTH})$ (PhenSQ)]PF 6 after illumination at $10 \mathrm{~K}$ can be reasonably fitted with the above expression with best fitting parameters $\beta=0.4$ and $\tau=1 / \mathrm{K}(\mathrm{T})=2.10^{5} \mathrm{~s}{ }^{48}$ (Figure 3) The observed kinetic constant is consistent with that predicted by the theory for a pure tunneling process under the hypothesis of small electronic coupling. Indeed structural data showed that the difference in the Co-O bond lengths between the $\mathrm{Co}^{\mathrm{III}}$-Cat isomer and the $\mathrm{Co}^{\mathrm{II}}-\mathrm{SQ}$ one (this parameter was obtained from the crystal structure of the nickel(II)semiquinonato analogue $)^{57}$ is $0.18-19 \AA$ and the Co-O stretching frequency is close to $300 \mathrm{~cm}^{-1}$. The latter hypothesis is supported by the large value of the average relaxation time measured at room temperature for the $\left[\mathrm{Co}^{\mathrm{III}}\left(\mathrm{Me}_{4} \text { cyclam }\right)(\mathrm{Cat})\right]^{+}$species in solution. ${ }^{36}$

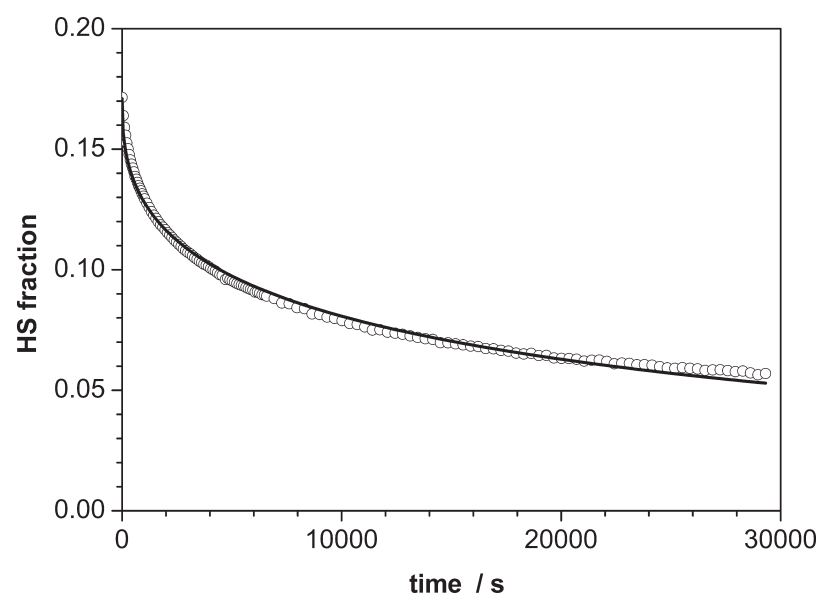

Figure 3. Relaxation curve of $[\mathrm{Co}(\mathrm{CTH})(\mathrm{PhenSQ})] \mathrm{PF}_{6}$ after illumination at $10 \mathrm{~K}$. The best fit is obtained with a stretched exponential decay.

The observed relaxation properties of the $[\mathrm{Co}(\mathrm{CTH})(\mathrm{PhenSQ})] \mathrm{PF}_{6}$ species well agree with those observed for [Co ${ }^{\mathrm{III}}$ (phen)(DBCat)(DBSQ) $] \cdot \mathrm{C}_{6} \mathrm{H}_{5} \mathrm{CH}_{3}$ and $\left[\mathrm{Co}{ }^{\text {III }}\right.$ (tmeda)(DBCat)(DBSQ) $] \cdot \mathrm{C}_{6} \mathrm{H}_{5} \mathrm{CH}_{3}$ complexes. ${ }^{38-40}$ For these systems the rate constants at $5 \mathrm{~K}$ were $5 \times 10^{-5}$ $\mathrm{s}^{-1}$ and $1 \times 10^{-4} \mathrm{~s}^{-1}$, which are also well consistent with a pure tunneling relaxation process. In a more recent article Sato and coworkers reported the analysis of the relaxation kinetics of the $\left[\mathrm{Co}^{\mathrm{II}}(\mathrm{phen})(\mathrm{DBSQ})_{2}\right] \cdot \mathrm{C}_{6} \mathrm{H}_{5} \mathrm{Cl}$ after its generation as metastable species..$^{58} \mathrm{~A}$ thermally activated relaxation behavior was obtained for $\mathrm{T}>25 \mathrm{~K}$ with $\mathrm{E}_{\mathrm{a}}=$ $110 \mathrm{~cm}^{-1}$, while an almost temperature independent relaxation was observed at lower temperature. At $5 \mathrm{~K}, \mathrm{~K}$ 
was found equal to $1.48 \times 10^{-4} \mathrm{~s}^{-1}$, a value which is fully consistent with the previously reported ones for similar $\mathrm{Co}(\mathrm{N}-\mathrm{N})(\text { diox })_{2}$ systems. ${ }^{38-40}$ We note here that the low value of the observed activation energy cannot be justified with the assumption of an interconversion mechanism based on the symmetric breathing mode of the complex, which is expected to be significantly higher in energy.

This conclusion is supported by the analysis of the relaxation kinetics of a related system we have recently synthesized. This is 1,10-phenanthroline-cobalt adduct of the dioxolene ligand 3,5-bis(3',4'-dihydroxy-5' -tert-butylphenyl)-1-tert-butyl-benzene, (L) (Scheme 5),<smiles>CC(C)(C)c1cc(-c2cc(O)c(O)c(C(C)(C)C)c2)cc(-c2cc(O)c(O)c(C(C)(C)C)c2)c1</smiles>

\section{Scheme 5.}

which, according to its geometry may act as bis-bidentate ligand towards two different metal ions and afford a polymeric system. ${ }^{59}$ The temperature dependence of the magnetic susceptibility (Figure 4) and the EPR spectra were found consistent with the existence of the valence tautomeric equilibrium:

$$
\begin{aligned}
\left.\left\{[\text { phen }) \mathrm{Co}^{\mathrm{II}}\right]_{1 / 1}-\mu-(\text { Cat }-S Q)-\left[C \mathrm{Co}^{\mathrm{II}}(\text { phen })\right]_{1 / 2}\right\}_{\infty} \\
\rightleftarrows\left\{\left[(\text { phen }) \mathrm{Co}^{\mathrm{II}}\right]_{1 / 2}-\mu-(\mathrm{SQ}-\mathrm{SQ})-\left[\mathrm{Co}^{\mathrm{II}}(\text { phen })\right]_{1 / 2}\right\}_{\infty}
\end{aligned}
$$

The thermal interconversion was found to be characterized by a significant thermal hysteresis ( $>12$

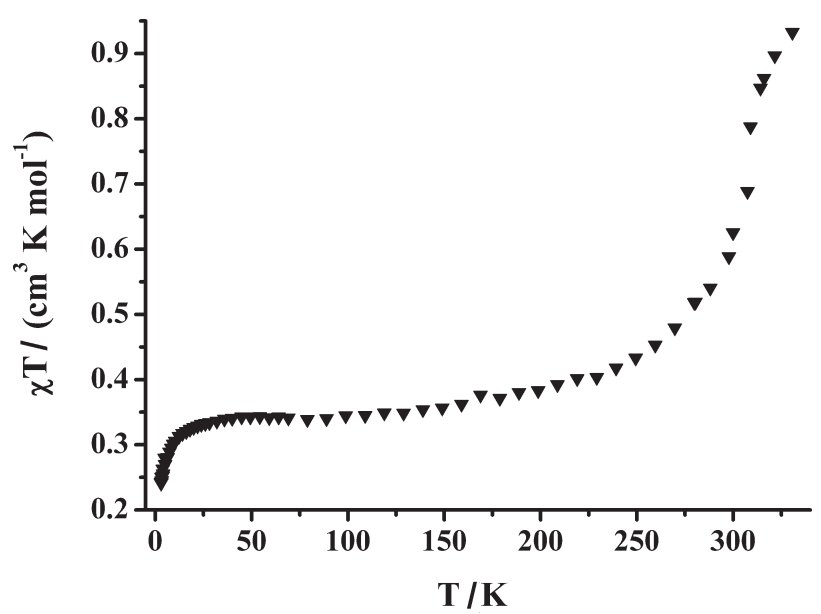

Figure 4. Temperature dependence of the $\chi \mathrm{T}$ product for the 1,10 phenanthroline-cobalt adduct of the dioxolene ligand 3,5-bis(3',4'dihydroxy-5'-tert-butyl-phenyl)-1-tert-butyl-benzene, showing the occurrence of the valence tautomer transition around $300 \mathrm{~K}$.
$\mathrm{K})$, thus supporting the achievement of a molecular system with enhanced cooperativity.

In order to investigate the effect of cooperativity on the kinetics of relaxation of $\mathrm{Co}(\mathrm{N}-\mathrm{N})(\operatorname{diox})_{2}$ complexes, the compound was irradiated at different wavelengths. We found that irradiation with the $658 \mathrm{~nm}$ was more effective for inducing changes in magnetic susceptibility. ${ }^{60}$ The thermal relaxation of the converted fraction versus time plots at four different temperatures are shown in Figure 5. The parameters describing the relaxation rate were fitted by assuming a stretched exponential decay law. We wish to note that in this case the reliability of this model for the relaxation analysis is further strengthened by the polymeric character of the sample, resulting in a distribution of chains of different lengths.

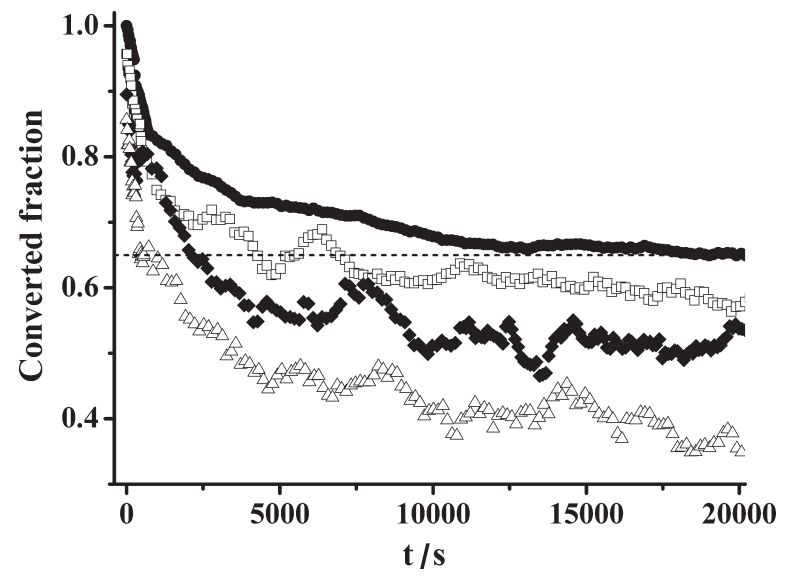

Figure 5. Relaxation kinetics of $\left\{\left[(\mathrm{phen}) \mathrm{Co}^{\mathrm{II}}\right]_{1 / 2}-\mu-(\mathrm{SQ}-\mathrm{SQ})-\right.$ $\left.[\mathrm{Co}(\text { phen })]_{1 / 2}\right\}_{\infty}$ at different temperatures, normalized values ( $\mathrm{t}=0$, conv. fract $=1 ; \mathrm{t}=\infty$, conv. fract. $=0$ ). Full circles: $9 \mathrm{~K}$; empty squares: $20 \mathrm{~K}$; full squares: $30 \mathrm{~K}$; empty triangles: $40 \mathrm{~K}$. The dashed line evidences the different times at which the same converted fraction $(0.65)$ is maintained.

Reasonably good fits performed fixing $\beta=0.3$, gave average relaxation times of $3.1 \pm 0.1 \times 10^{5} \mathrm{~s}$ at $9 \mathrm{~K}, 1.5 \pm$ $0.1 \times 10^{5} \mathrm{~s}$ at $20 \mathrm{~K}, 7.5 \pm 0.3 \times 10^{4} \mathrm{~s}$ at $30 \mathrm{~K}$ and $1.6 \pm 0.2 \times 10^{3}$ $\mathrm{s}$ at $40 \mathrm{~K}$. The features we observed were similar to those reported by Sato and coworkers, ${ }^{58}$ with some remarkable differences. From the comparison of these data with those reported for mononuclear $\mathrm{Co}(\mathrm{N}-\mathrm{N})(\operatorname{diox})_{2}$, it is rather clear that relaxation of the photoinduced metastable state to the ground state is significantly slower in this compound than in the other investigated mononuclear systems. Even if the observed relaxation behavior can be reasonably reproduced by a stretched exponential decay we believe that this result can be attributed to the presumed one-dimensional cooperativity existing in this compound. Indeed systems characterized by three-dimensional cooperativity have been found to exhibit a significantly more complicated behavior (sigmoidal-shaped curves). ${ }^{52,61}$ The result we obtained unambiguously shows how an appropriate ligand design can deeply influence in a defined direction the physical properties of this class of compounds. 
The analysis of relaxation rates showed that there exists a marked temperature dependence of the relaxation rate at $30-40 \mathrm{~K}$ with $\mathrm{E}_{\mathrm{a}}$ value of $90 \mathrm{~cm}^{-1}$. However also in the tunneling regime $(10-20 \mathrm{~K})$ a small temperature dependence with $\mathrm{E}_{\mathrm{a}}=20 \mathrm{~cm}^{-1}$ was observed. The latter observation and the small $\mathrm{E}_{\mathrm{a}}$ values suggest that a latticephonon assisted mechanism can be active. Therefore even if the hypothesis of a tunneling process involving essentially the ground vibrational level of the Co-O mode holds, we suggest that this main process is associated with other low energy vibrations. The low energies of the lattice phonons $\left(5-10 \mathrm{~cm}^{-1}\right)$ are suggested to control the lifetimes of the photoinduced metastable species. The same conclusion can be drawn from the previously discussed data obtained for $\left[\mathrm{Co}^{\mathrm{II}}(\mathrm{phen})(\mathrm{DBSQ})_{2}\right] \cdot \mathrm{C}_{6} \mathrm{H}_{5} \mathrm{Cl}$ complex..$^{58}$ We believe that these results are relevant for understanding the key parameters governing the low temperature lifetimes of the photoinduced metastable species.

\section{Concluding Remarks}

The above discussed experimental results suggest that optical induced valence tautomeric interconversion is a general property of cobalt-dioxolene complexes, even if the number of systems investigated to date is rather limited. It can be also suggested that the observed properties well fit the requirements necessary for their application in the design of electronic devices. The attractiveness of these systems is given by the fact that the interconversion process may involve a single molecule and not a collection of centers. In this sense the lowest dimensional limit of an electronic device has been achieved. The intrinsic limit is constituted by the fast decay rates of the photoinduced metastable states above $20 \mathrm{~K}$. Theory predicts that the simplest strategies for overcoming this problem should be the increase of the difference between metal-oxygen bond lengths in the two forms and the decrease of the zero-energy difference between the two electronic states. The former is limited by the chemical nature of the systems themselves, whereas we think that it is possible to modulate the energy differences by molecular techniques and we are focusing our research in that direction.

More interesting perspectives in the field could be achieved by designing systems exhibiting strong cooperative interactions. This of course would cause the loss of the single molecule nature of the process, but could open different important perspectives due to possible thermal hysteresis of magnetic properties. Finally we believe a further promising possibility is controlling the interconversion between the two forms by exploiting the steric requirements of the ancillary ligands.
The present contribution represents the first reviewing manuscript about this topic. However the research activity in this specific field is rapidly growing and there is no doubt that future work will show how the potential perspectives here discussed might provide some fruitful results.

\section{Acknowledgments}

The financial support of NE MAGMANET NMP3CT-2005 515767 is gratefully acknowledged.

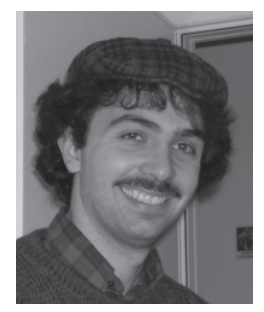

Lorenzo Sorace was born in 1974 and received the Degree in Chemistry from the University of Florence in 1998. In 2001 he received the $P h . D$. in Chemistry at the same University with a thesis on "Magnetism and magnetic anisotropy of spin clusters". After a post-doctoral period at the CNRS in Grenoble devoted to the study of spin dynamics of single molecule magnets under microwave irradiation he came back to University of Florence where he is currently a temporary researcher. $H e$ is mainly interested in the use of EPR spectroscopy for the analysis of the properties of molecular magnets.

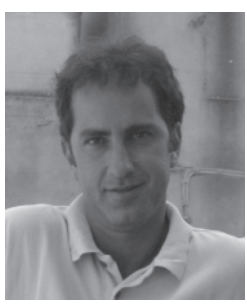

Claudio Sangregorio graduated in Chemistry at the University of Florence in 1994 and in 1997 obtained the PhD in Material Science at the same institution with a thesis on magnetic nanoparticles. After a post-doc at the AMRI institute in New Orleans (USA), in 1999 he moved back to the University of Florence, at the Laboratory for Molecular Magnetism, where at present he has a position as researcher. His research interests are in the field of nanosized magnetic materials, ranging from metal or metal oxide based nanocomposites to high spin molecular clusters.

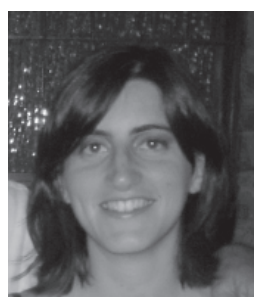

Alessandra Beni graduated in Chemistry at the University of Florence in 2003 and is currently a PhD student in Material Science at the Laboratory of Molecular Magnetism in Florence, under the supervision of Prof A. Dei. Her research activity focuses on the study of bistable paramagnetic systems showing valence tautomerism and in particular on the photomagnetic properties of these systems, studied by different experimental techniques. 


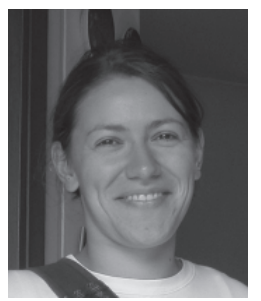

Chiara Carbonera graduated in Industrial Chemistry in 1999 from the University of Milano Statale. In 2003 she got her PhD in Chemistry in the University of Florence, working on magnetic properties of rare earth and transition metals containing systems. She continued her activity at the Institute of Condensed Matter Chemistry of Bordeaux (ICMCB) as a post-doctoral researcher (2003-2006), focussing on the experimental study of photomagnetism. In 2006, she obtained a Juan de la Cierva Fellowship to work on magnetic properties of nanoparticles in the Institute of Materials Sciences of Aragon, belonging to the University and CSIC of Zaragoza.

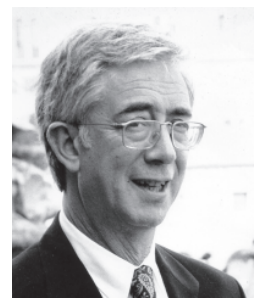

Andrea Dei is Associate Professor in Inorganic Chemistry at the University of Florence since 1981. His current research interests are focused on synthesis of new metal dioxolene complexes acting as potential building blocks for molecular based magnetic materials and/or as electronic bistable molecules.

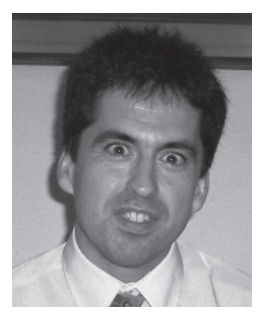

Dr. Jean François Létard studied Chemistry and Photochemistry at the University of Bordeaux. He received his doctorate in 1994 and then obtained an Alexander Von Humboldt fellow at the University of Mainz to work in the group of Professor Gütlich. In 1995 he was appointed as CNRS researcher and joined the Molecular Sciences Group of late Professor Kahn at the ICMCB. In 2000, he completed his Habilitation and since 2004 he is head of the Molecular Sciences Group. His main research interest is the elaboration of spin crossover materials with particular emphasis on photomagnetism and on molecular bistability in connection with industrial applications.



Roberto Righini was born in Florence in 1947 and is Professor of Chemical Physics since 1981 at the University of Florence. Since 2005 he is director of the European laboratory of Non linear spectroscopy (Lens). His research activity is devoted to subpicoseond spectroscopy for the study of liquid structures and of the dynamics of relaxation involving optically excited states of the molecules. He is author of more than hundred publications including outstanding contributions in the most important scientific journals.

\section{References}

1. Feringa, B. L.; Molecular Switches, Wiley-VCH: Weinheim, 2001.

2. De Silva, A. P.; McClenaghan, N. D.; Chem. Eur. J. 2004, 10, 574.

3. Irie, M. (Guest ed.); Chem. Rev. 2000, 100, 1683.

4. Kahn, O.; Molecular Magnetism, Wiley-VCH: Weinheim, 1993.

5. Miller, J. S.; Drillon, M. eds.; Magnetism: Molecules to Materials, Wiley-VCH: Weinheim, 2001.

6. Gütlich, P.; Garcia, Y.; Woike, T.; Coord. Chem. Rev. 2001, $219,839$.

7. Sato, O.; Acc. Chem. Res. 2003, 36, 692.

8. Fernandez-Acebes, A. ; Lehn, J.-M.; Chem. Eur. J. 1999, 5, 3285.

9. Takayama, K.; Matsuda, K.; Irie, M.; Chem. Eur. J. 2003, 9, 5605.

10. Pejakovic, D. A.; Kitamura, C.; Miller, J. S.; Epstein, A. J.; Phys. Rev. Lett. 2002, 88, 57202.

11. Sato, O.; J. Photochem. Photobiol. 2004, 5, 203.

12. Dei, A.; Angew. Chem. Int. Ed. Engl. 2005, 44, 1160.

13. Gütlich, P.; Hauser, A.; Spiering, H.; Angew. Chem. Int. Ed. Engl. 1994, 33, 2024.

14. Gütlich, P.; Garcia, Y.; Goodwin, H. A.; Chem. Soc. Rev. 2000, 29, 419.

15. Evangelio, E.; Ruiz-Molina, D.; Eur. J. Inorg. Chem. 2005, 2957.

16. Hendrickson, D. N.; Pierpont, C. G.; Top. Curr. Chem. 2004, 234,63

17. Dei, A.; Gatteschi, D.; Sangregorio, C.; Sorace, L.; Acc. Chem. Res. 2004, 37, 827

18. Pierpont, C. G. ; Coord. Chem. Rev. 2001, 219, 99.

19. Shultz, D. A. In Magnetism: From Molecules to Materials; Miller, J. S.; Drillon, M.: eds., Wiley-VCH: Weinheim, 2001.

20. Gütlich, P.; Dei, A.; Angew. Chem. Int. Ed. Engl. 1997, 36, 2734.

21. Pierpont, C. G.; Lange, C. W.; Prog. Coord. Chem. 1993, 41, 381

22. Pierpont, C. G.; Buchanan, R. M.; Coord. Chem. Rev. 1981, $38,45$.

23. Buchanan, R. M.; Pierpont C. G.; J. Am. Chem. Soc. 1980, 102, 4951.

24. Adams, D. M.; Dei, A.; Rheingold, A. L.; Hendrickson, D. N.; J. Am. Chem. Soc. 1993, 115, 8221.

25. Jung, O.-S.; Pierpont, C. G.; Inorg. Chem. 1994, 33, 2227.

26. Roux, C.; Adams, D. M.; Itiè, J. P.; Polian, A.; Hendrickson, D. N.; Verdaguer, M.; Inorg. Chem. 1996, 35, 2846.

27. Caneschi, A.; Dei, A.; Fabrizi de Biani, F.; Gütlich, P.; Ksenofontov, V.; Levchenko, G.; Hoefer, A.; Renz, F.; Chem. Eur. J. 2001, 7, 3926.

28. Adams, D. M.; Li, B.; Simon, J. D.; Hendrickson, D. N.; Angew. Chem. Int. Ed. Engl. 1995, 34, 1981. 
29. Adams, D. M.; Hendrickson, D. N.; J. Am. Chem. Soc. 1996, 118,11515

30. Buhks, E.; Navon, G.; Bixon, M.; Jortner, J.; J. Am. Chem. Soc. 1980, 102, 2918.

31. Larsen, S. K.; Pierpont, C. G.; J. Am. Chem. Soc. 1988, 110, 1827.

32. Cador, O.; Chabre, F.; Dei, A.; Sangregorio, C.; Van Slageren, J.; Vaz, M. G. F.; Inorg. Chem. 2003, 42, 6432.

33. Caneschi, A.; Cornia, A.; Dei, A.; Inorg. Chem. 1998, 37, 3419.

34. Gentili, P. L.; Bussotti, L.; Righini, R.; Beni, A.; Bogani, L.; Dei, A.; Chem. Phys. 2005, 314, 9.

35. Neuwahl, F. V. R.; Righini, R.; Dei, A.; Chem Phys. Lett. 2002, 352, 408.

36. Bencini, A.; Caneschi, A.; Carbonera, C.; Dei, A.; Gatteschi, D.; Righini, R.; Sangregorio, C.; Van Slageren, J.; J. Mol. Struct. 2003, 656, 141.

37. Adams, D. M.; Dei, A.; Rheingold, A. L.; Hendrickson, D. N.; Angew. Chem. Int. Ed. Engl. 1993, 32, 880.

38. Sato, O.; Hayami, S.; Gu, Z.-Z.; Seki, K.; Nakjima, R.; Fujishima, A.; Chem. Lett. 2001, 874

39. Sato, O.; Hayami, S.; Gu, Z.-Z.; Takahashi, K.; Nakjima, R.; Fujishima, A.; Chem. Phys. Lett. 2002, 355, 169.

40. Varret, F.; Nogues, M.; Goujon, A. In Magnetism: Molecules to Materials; Miller, J. S.; Drillon, M.; eds., Wiley-VCH: Weinheim, 2001.

41. Yokoyama, T.; Okamoto, K.; Nagai, K.; Ohta, T.; Hayami, S.; Gu, Z.-Z.; Nakajima, R.; Sato, O.; Chem. Phys. Lett. 2001, 34, 272.

42. Sato, O.; Hayami, S.; Gu, Z.-Z.; Takahashi, K.; Nakajima, R.; Seki, K.; Fujishima, A.; J. Photochem. Photobiol. A 2002, 149, 111.

43. Decurtins, S.; Gütlich, P.; Köhler, C. P.; Spiering, H.; Hauser, A.; Chem. Phys. Lett. 1984, 105, 1.
44. Hauser, A.; Chem. Phys. Lett. 1986, 124, 543.

45. Sato, O.; Iyoda, T.; Fujishima, A.; Hashimoto, K.; Science 1996, 272, 704.

46. Verdaguer, M.; Science 1996, 272, 698.

47. Cador, O.; Dei, A.; Sangregorio, C.; Chem. Commun. 2004, 625.

48. Carbonera, C.; Dei, A.; Sangregorio, C.; Letard, J.-F.; Chem Phys. Lett. 2004, 396, 198

49. Carbonera, C.; Dei, A.; Létard, J.-F.; Sangregorio, C.; Sorace, L.; Angew. Chem. Int. Ed. 2004, 43, 3136.

50. Tao, J.; Maruyama, H.; Sato, O.; J. Am. Chem. Soc. 2006, 128, 1790 .

51. Brady, C.; McGarvey, J. J.; McCusker, J. K.; Toftlund, H.; Hendrickson, D. N.; Top. Curr. Chem. 2004, 235, 1.

52. Hauser, A.; Top. Curr. Chem. 2004, 235, 155.

53. Hauser, A.; Vef, A.; Adler, P. J.; J. Chem. Phys. 1991, 95, 8710.

54. Hauser, A.; Comments Inorg. Chem. 1995, 17, 17.

55. Hauser, A.; Coord. Chem. Rev. 1991, 111, 275.

56. Chamberlin, R. V.; Mozurkewich, G.; Orbach, R.; Phys. Rev. Lett. 1984, 52, 867.

57. Bencini, A.; Carbonera, C.; Dei, A.; Vaz, M. G. F.; Dalton Trans. 2003, 1701.

58. Cui, A.; Takahashi, K.; Fujishima, A.; Sato, O.; J. Photochem. Photobiol. A 2004, 167, 69.

59. Bodnar, S. H.; Caneschi, A.; Dei, A.; Shultz, D. A.; Sorace, L.; Chem. Commun. 2001, 2150.

60. Beni, A.; Dei, A.; Shultz, D. A.; Sorace, L.; Chem. Phys. Lett. 2006, 428, 400.

61. Gawali-Salunke, S.; Varret, F.; Maurin, I.; Enachescu, C.; Malarova, M.; Boukhedadden, K.; Codjovi, E.; Tokoro, H.; Ohkoshi, S.; Hashimoto, K.; J. Phys. Chem. B 2005, 109, 8251.

Received: July 14, 2006 Published on the web: December 4, 2006 